A. L. STOFFERS

\title{
BOTANISCH ONDERZOEK VAN DE NEDERLANDSE ANTILLEN
}

Botanisch onderzoek van een gebied heeft als regel in drie fasen plaats:

I. floristisch onderzoek, teneinde een overzicht te krijgen van de plantensoorten, variëteiten en andere systematische eenheden die in het betreffende gebied gevonden worden;

2. vegetatie-onderzoek, om een overzicht te krijgen van de samenstelling van het plantendek;

3. oecologisch onderzoek, om tot een causale verklaring van die vegetatie te komen.

Deze drie fasen zijn in de Nederlandse Antillen ook te onderscheiden en zullen daarom achtereenvolgens besproken worden.

\section{FLORISTISCH ONDERZOEK}

Benedenwindse Eilanden

Voor de Benedenwindse Eilanden worden de eerste floristische gegevens reeds vóór I753 gevonden (o.a. bij Plukenet, I696). Linnaeus (I753) vermeldt in zijn 'Species Plantarum' expliciet 20 soorten voor Curaçao en I soort voor Aruba. Hieronder vinden we soorten waaraan geen twijfel behoeft te bestaan dat zij op het eiland Curaçao voorkwamen, zoals bembe di porco (Trianthema portulacastrum), manzanilla bobo (Euphorbia cotinifolia), pega saja bobo (Cenchrus echinatus) en de cactus-soorten cadushi di colebra (Acanthocereus tetragonus), cadushi di pushi (Cephalocereus lanuginosus), en librá (Opuntia curassavica). Bij andere soorten moet echter een vraagteken geplaatst worden zoals komtsji koe skotter (Asclepias curassavica), een soort die tegenwoordig alleen gekweekt op de Benedenwindse Eilanden voor-

Uitgewerkte lezing gehouden op 27 november 1965, ter gelegenheid van het 20-jarig bestaan van de 'Natuurwetenschappelijke Studiekring voor Suriname en de Nederlandse Antillen'. 
komt en Grewia occidentalis (Tiliaceae) een soort die alleen in Afrika voorkomt. In de 'Species Plantarum' vinden we verder nog enige soorten die weliswaar niet speciaal voor de eilanden genoemd worden, maar waarvan men mag aannemen dat zij wel van dit gebied bekend waren, o.a. kokolodé shimaron (Heliotropium curassavicum), "Habitat in America calidioris maritimis". We kunnen aannemen, dat in I753 ongeveer 30 soorten van de Benedenwindse Eilanden in de literatuur bekend waren.

Een aanvulling geeft JAcoUIN (I763) met een I3-tal soorten, o.a. palu di sía (Bursera tomentosa), mata di piscá (Jacquinia barbasco), bai no bolbe (Strumpfia maritima) en dal pega (Menzelia aspera). Afgezien van de twee min of meer toevallige bezoeken van von ROHR en van BREDEMEYER, wordt er in de loop van de $18 \mathrm{e}$ eeuw niets meer toegevoegd aan de botanische kennis van dit gebied. Het blijft 'rustig' tot $\mathrm{I} 885$, het jaar waarin W. F. R. SuRINGar de eilanden bezocht en een collectie bijeen bracht die in het Rijksherbarium te Leiden wordt bewaard. SURINGAR richtte - evenals later ook zijn zoon J. VALCKENIER SURINGAR zijn aandacht in het bijzonder op het geslacht Melocactus. Deze studies resulteerden in het onderscheiden van niet minder dan $8 \mathrm{I}$ soorten, 2I varieteiten en 8 vormen van dit genus op de Benedenwindse Eilanden.

Van groot belang voor het floristisch onderzoek zou het bezoek van de Utrechtse hoogleraar F. A. F. C. WENT in I9or blijken te zijn. Niet om de collectie die hij bijeen wist te brengen, maar vooral omdat WENT de Utrechtse botanicus I. BoLDINGH in staat stelde in I909/I9Io de eilanden te bezoeken. Diens resultaten zijn verwerkt in het standaardwerk 'Flora voor de Nederlandsch West-Indische Eilanden' (I9I3) en in 'The Flora of Curaçao, Aruba and Bonaire' (I9I4). Naast een opsomming van de soorten bevat dit laatste werk ook plantengeografische en enige oecologische en vegetatiekundige aantekeningen. Bij het verschijnen van BoLDINGH's 'Flora' waren 3 varens en 380 zaadplanten bekend van de Benedenwindse Eilanden.

Incidenteel, maar waardevol onderzoek is tussen I9I3 en 1945 te noemen. De cactussen en agaves werden bestudeerd door WAGENAAR HUMmelincK (I933-I94I). AMSHOFF (I942) verzorgde een nieuwe bewerking van de grassen. Een viertal endemen, soorten dus met een tot de Benedenwindse Eilanden beperkte verspreiding, werden beschreven uit de Boldingh-collectie: Aristida arubensis (HENRARD, I926), Lantana arubensis (MOLDENKE, I940), 
Stachytarpheta boldinghii (Moldenke, I940) en Paspalum bonairense (HENRARD, I943). ChASE (I943) beschreef een nieuw gras: Paspalum curassavicum.

De plaatselijke belangstelling voor de natuur werd vooral levendig gehouden door frater Realino Janssen. Belangrijker dan de uitgave van zijn 'Plantkunde van Curaçao voor M.U.L.O.' (I935) was misschien wel het feit dat hij zijn belangstelling voor de biologie aan zijn medebroeder frater ARNOLDO BROEDERS wist over te dragen. ARNoldo's interesse ging vooral uit naar de plantkunde. Hij begon met een collectie bijeen te brengen en kwam daarbij tot de conclusie, dat contact met een op ZuidAmerika gespecialiseerd plantensystematisch instituut onontbeerlijk was. Het contact dat ARNOLDo met het Botanisch Museum en Herbarium van de R.U. te Utrecht opnam, bleek een gunstig effect te hebben. De grote wilskracht en het doorzettingsvermogen van ARNOLDO, samen met de hem door Utrecht geboden hulp, maakten de publicatie van de 'Zakflora' (1954) en de 'Gekweekte en nuttige planten van de Nederlandse Antillen' (1954) - beide als Uitgaven van de Natuurwetenschappelijke Werkgroep Nederlandse Antillen - mogelijk.

ARNOLDO's collectie toonde al spoedig aan, dat een revisie van Boldingh's 'Flora' gewenst was. Deze revisie, alsmede een vegetatie-onderzoek werd in I95I door de Natuurwetenschappelijke Studiekring voor Suriname en de Nederlandse Antillen aan A. L. Stoffers opgedragen. De collecties van Boldingh, ARnoldo en STOFFERS vormen het uitgangsmateriaal van de 'Flora of the Netherlands Antilles', waarvan de eerste aflevering in I962 verscheen met een bewerking van de varens door K. U. KRAMER. Van de zaadplanten zijn nieuwe bewerkingen van 25 families reeds verschenen, terwijl het merendeel van de resterende families bewerkt is. Zodoende is het mogelijk nu reeds een indruk te geven van de betekenis van de nieuwe collecties als bijdrage tot de floristische kennis van de Benedenwindse Eilanden. Tegenover de 3 varens en 380 zaadplanten welke door BoLDINGH vermeld werden, zijn nu 5 varens, 484 soorten en 7 variëteiten bekend, een toename dus van ro6 soorten en 7 variëteiten. Hieronder zijn vier endemen te noemen: Xylosma arnoldii Monachino (I947), Aulomyrcia curassavica Amshoff (I950), Sorocea arnoldoi Lanjouw \& Wessels Boer (I962) en Alternanthera arnoldiana Stoffers (1963a). 
Van algologische zijde is lange tijd slechts weinig aandacht aan de Benedenwindse Eilanden besteed. De door J. BoEKE in I905 verzamelde wieren werden door SLUITER (I908) gepubliceerd; TAYLOR (I942) geeft resultaten van de bezoeken van Amerikanen aan Aruba en Curaçao. FrÉmY (I94I) bewerkte de door WAGENAAR HUMMELINCK in I930 verzamelde Blauwwieren, evenals KoSTER (I960) dit van zijn latere collecties deed. VAN DEN HoEK (1959) bewerkte een deel van zijn zoet- en brakwater Groenwieren.

Een onderzoek naar het voorkomen en de oecologie van mariene wieren werd door VROMan ingesteld in de jaren r957/58. Het totaal aantal soorten Groen-, Rood- en Bruinwieren wordt door hem (1959) op ongeveer 250 geschat. Een overzicht van de mariene algen gaf Díaz-PIFERRER in I964.

De mossen kregen tot voor kort in het geheel geen aandacht. Een bewerking van het door ARNOLDO en STOFFERS verzamelde materiaal, door de Utrechtse bryoloog P. A. FLoRSchüTZ, verscheen in 1967 .

\section{Bovenwindse Eilanden}

Voor de Bovenwindse Eilanden gaan de eerste gegevens terug tot JAcQuin (I763), die voor St. Eustatius 6 soorten, voor St. Maarten 5 soorten vermeldt, maar Saba in het geheel niet noemt. Opvallend is het bezoek van verscheidene Franse en Deense botanici. SURINGAR en WENT bezochten de eilanden, maar evenals op de Benedenwindse Eilanden wordt ook hier het eerste, systematisch opgezette onderzoek door BoLDINGH, in I906, verricht. Het resultaat is weergegeven in 'The Flora of St. Eustatius, Saba and St. Martin' (1909) en de reeds genoemde 'Flora voor de Nederlandsch West-Indische Eilanden' (I9I3). Als belangrijkste collecties na I945 mogen genoemd worden die van ARNOLDo (I947I965) en Stoffers (I953). Ondanks deze collecties mogen wij aannemen dat de flora van de Bovenwindse Eilanden aanmerkelijk minder goed bekend is dan die van de Benedenwindse Eilanden. Geeft BoLdINGH (I909) reeds 52 varens en 622 bloemplanten voor de drie eilanden, met de laatste collecties konden voor St. Maarten 7 zaadplanten, voor Saba 6 varens en 2I zaadplanten en voor St. Eustatius slechts I varen en 4 zaadplanten aan de lijst worden toegevoegd.

De wieren werden in I958 door VROMAN voor het eerst bestudeerd. 
Een eerste publicatie over de mossen van de Bovenwindse Eilanden is onlangs verschenen (FLORSCHÜTZ, I967).

\section{VEGETATIE-ONDERZOEK}

Grote vorderingen heeft het vegetatie-onderzoek in de laatste twintig jaar gemaakt. BoldingH (I9I4) onderscheidde op de Benedenwindse Eilanden een littorale vegetatie, een kustvegetatie dus, die moeilijk te onderscheiden is van de hoofdvegetatie, de Croton-vegetatie. Deze Croton-vegetatie wordt vooral bepaald door welisali (Croton flavens) en wabi (Acacia tortuosa), maar komt in twee typen voor. Op de kalkplateau's een placa chiquitu - cuchara type (Rhacoma crossopetalum Antirrhoea acutata type) en buiten het kalkgebied een oliba (Capparis cynophallophora) type. Voor de Bovenwinden komt BoLDINGH (I909) tot het onderscheiden van:

$a$. een Eriodendron-vegetatie: een bos-vegetatie, te vinden op St. Eustatius op de hoger gelegen hellingen van The Quill en in de dalen in het N.W. deel; op St. Maarten als bosresten nabij de toppen van verschillende heuvels; op Saba in de ravijnen en op de lager gelegen hellingen, alsmede - zij het in een enigszins afwijkende vorm - op de hoger gelegen hellingen van The Mountain. $b$. een Croton-vegetatie: de uit lage en hoge heesters opgebouwde vegetatie in de vlakke delen en de lager gelegen hellingen van St. Eustatius en St. Maarten. [Op Saba wordt dit type slechts spaarzaam gevonden en is dan bovendien slecht ontwikkeld.]

c. een litt orale vegetatie: de begroeiing van de zandstranden, van de rotshellingen nabij de kust, en rond de lagunen en zoutpannen.

STOFFERS onderscheidde in 'The Vegetation of the Netherlands Antilles' (I956) een groter aantal typen, gebaseerd op een door BEARD (I944, I949, I955) voorgestelde indeling. In dit syteem wordt de vegetatie op drie niveau's ingedeeld:

a. FLORISTISCH: de associatie en gesubordineerde eenheden;

b. PHYSIOGNOMISCH: de formatie, gebaseerd op overeenkomsten in structuur. [De formatie is dus onafhankelijk van de flora, maar wordt bepaald door de levensvorm van de soorten die de vegetatie vormen. De formatie is een reactie op belangrijke a-biotische milieu-factoren (standplaats-factoren).]

c. STANDPLAATS: formatie-reeksen, waarbij elke reeks gekenmerkt wordt door een bepaalde standplaats-factor. [De betref- 
fende factor kan in elke gradatie tussen optimaal en minimaal aanwezig zijn en aldus bepalend zijn voor het tot stand komen van bepaalde formaties.]

Centraal in dit systeem staat het tropisch regenbos: de optimum formatie, een bosvegetatie welke onder optimale omstandigheden met betrekking tot de belangrijkste milieu-factoren tot stand is gekomen. Dit bos wordt gekenmerkt door een gecompliceerde structuur en altijd-groene soorten zonder xeromorphe aanpassingen. Er zijn drie boomlagen, een heester-, een kruidenen een bodemlaag te onderscheiden; het bovenste kroondak is gesloten. Vanuit deze optimum formatie stralen als het ware de formatie-reeksen uit met afnemende structuur en toenemende aanpassingen aan de meer extreme milieu-omstandigheden. BEARD (I955) onderscheidt vijf van dergelijke reeksen, waarvan er vier voor de eilanden van de Nederlandse Antillen in aanmerking komen:

a. De reeks van seizoen-formaties. - De tot deze reeks behorende formaties zijn aangepast aan droge tijden die in de loop van het jaar optreden. De formaties uit deze reeks worden in het Caraïbische gebied vooral beneden $300 \mathrm{~m}$ gevonden.

CHARTER (I94I) heeft er op gewezen dat wanneer de maandelijkse hoeveelheid neerslag minder wordt dan de hoeveelheid water die door verdamping verloren gaat, de groei van de plant beïnvloed wordt. Dit punt ligt bij roo mm neerslag per maand voor het Caraïbische gebied, een waarde die door HARDY (1946) op Trinidad (en ook door MoHR (1944) op Java) experimenteel bevestigd werd. Naarmate het aantal achtereenvolgende droge maanden groter wordt, komt de aanpassing aan deze meer extreme omstandigheden sterker tot uiting door het optreden van een hoger percentage loofverliezende soorten, het optreden van gedoornde en gestekelde soorten en tenslotte door het optreden van succulenten. De structuur wordt bovendien minder gecompliceerd en de laatste (zesde) formatie in deze reeks is de woestijn. De eerste twee formaties in de reeks vertonen nog veel overeenkomsten met het regenbos: het bovenste kroondak wordt open en het middelste wordt gesloten (Evergreen Seasonal Formation); in de volgende formatie is deze laag verdwenen en bestaat het bos uit twee boomlagen (Semi-deciduous Seasonal Formation). De derde formatie (Deciduous Seasonal Formation) bestaat uit twee boomlagen, waarvan het bovenste kroondak open is. Achtereenvolgens komen dan nog het doornig kreupelhout (Thorn woodland), het cactus struweel (Cactus scrub) met heesters en succulenten, en tenslotte de woestijn met een zeer open, spaarzame begroeiïng.

b. De reeks van droge altijd-groene formaties. - De formaties van deze reeks worden ook vooral beneden $300 \mathrm{~m}$ gevonden, maar zij zijn meer een uiting van physiologische droogte, 

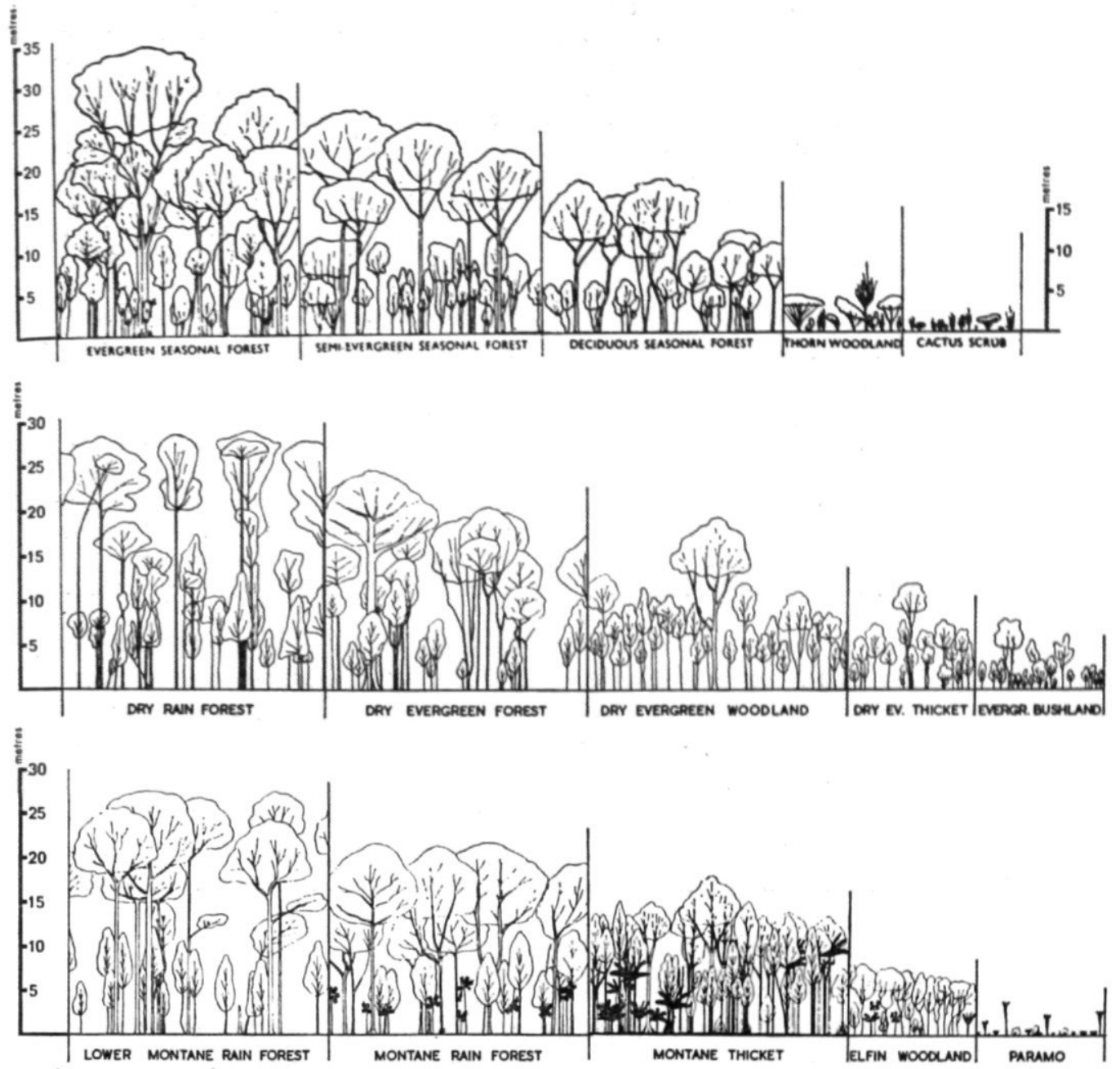

FIG. 3. Schematische voorstelling van de drie op de Nederlandse Antillen voorkomende formatie-reeksen welke door BEARD bij zijn vegetatieonderzoek worden onderscheiden : seizoen-formaties (boven), droge altijdgroene formaties (midden), montane formaties (onder) [uit Ecology 36, 1955].

vooral veroorzaakt door een uitdrogende wind, gebrek aan bewortelingsmogelijkheid en geringe regenval zonder seizoenvariaties.

Kenmerkend voor de formaties is het voorkomen van altijd-groene bomen en heesters, met leerachtige of harde bladeren, vaak voorzien van olie- 
klieren en een afschilferende schors. Microphyllie komt onder meer extreme omstandigheden veelvuldig voor, maar gedoornde en gestekelde soorten zijn niet aanwezig. De reductie in de structuur vindt niet plaats door openen van een gesloten kroonlaag en het sluiten van de daaronder liggende laag zoals in de vorige reeks. We houden hier steeds twee lagen, waarvan de bovenste laag open en de daaronder liggende laag gesloten is; de ondergroei is gering. Naarmate de milieu-omstandigheden ongunstiger worden wordt de hoogte van deze lagen geringer. Slechts de 'vegetation of the rock pavement' wordt gekenmerkt door onregelmatige, open groei van verspreide heesters op de kale rotsen.

c. De reeks van montane formaties. - De hiertoe behorende formaties worden gevonden op hoger gelegen berghellingen. Waarschijnlijk is expositie de belangrijkste factor voor het tot stand komen hiervan en niet de hydratuur.

Het is niet waarschijnlijk dat in het Caraïbische gebied de temperatuur een doorslaggevende rol speelt (BEARD, r949). Ook in deze reeks treedt een geleidelijke reductie van de hoogte der kroonlagen op. De bovenste kroonlaag is gesloten en valt aan het einde van de reeks ongeveer samen met de ondergroei. Opvallend is dat microphyllie hier niet optreedt. De bladeren zijn vaak leerachtig en dik en begroeid met epiphylle mossen.

d. Moeras formaties. - In deze reeks zijn opgenomen de vegetaties op regelmatig door zoet- of zoutwater overspoelde bodems, die niet onderhevig zijn aan periodieke uitdroging. Hiervoor komen op onze eilanden alleen de mangrove bossen in aanmerking.

Deze formaties moeten beschouwd worden als eindpunten in een vegetatie-ontwikkeling (successie), als climaces. Hiernaast dienen nog secundaire vegetaties, subclimaces en successie-stadia te worden onderscheiden.

\section{Bovenwindse Eilanden.}

De vegetatie van de Bovenwindse Eilanden kan met enige aanvullingen geheel ingepast worden in het hierboven in het kort weergegeven systeem. Het echte tropische regenbos, zoals dit bekend is van de grotere eilanden van de Antillen-boog, wordt echter niet meer gevonden.

Het was vroeger waarschijnlijk op Saba aanwezig tussen 400 en $600 \mathrm{~m}$ hoogte, waar we nu een vegetatie vinden, welke als secundair regenbos beschouwd moet worden. Tussen een aantal voor regenbos karakteristieke soorten komen soorten voor die herinneren aan de vroegere plantages: Citrus, breadfruit (Artocarpus), cacao (Theobroma cacao), guyaba (Psidium guajava), koffie (Coffea arabica), Annona spp, zoals zuurzak en custard apple, en mamaya (Mammea americana).

Een tweede type van secundaire vegetatie wordt hier gevormd door de boomvarens, die op Saba in een praktisch aaneengesloten gordel op de 
helling van The Mountain tussen 575 en $650 \mathrm{~m}$ gevonden worden in het gebied dat door hoge luchtvochtigheid gekenmerkt wordt. Slechts weinig soorten worden hier gevonden: Cyathea arborea, C. muricata en C. grandifolia. Als gevolg van de zeer geringe lichtintensiteit in deze vegetatie is een heester- en kruidenlaag totaal afwezig.

Naast deze over grote oppervlakten gevonden secundaire begroeiïngen worden op Saba zeer locaal nog andere secundaire vegetaties gevonden, waaronder de Miconia-, en de Piper dilatatum-vegetatie naast het pionierbos wel het meest opvallen. Het pionier-bos wordt gevormd door snelgroeiende planten zoals wild banana (Heliconia bihai), wild papaw ( $\mathrm{Ce}$ cropia peltata), blue berry (Symplocos martinicensis) en Acnistus arborescens. Dit pionier-bos kan beschouwd worden als een van de meest algemene kaalkap gezelschappen in het regenbos van tropisch Amerika.

Montane formaties. - De montane formaties worden vertegenwoordigd door het 'montane thicket' op St. Eustatius en het 'elfin woodland' op Saba en St. Eustatius.

Hiervan kan het 'montane thicket' gekenmerkt worden als een zeer open bos met één boomlaag, die op $\mathbf{1}_{2-15} \mathrm{~m}$ gesloten is. Een heesterlaag is afwezig, maar de kruidenlaag is zeer dicht en bedekt met de monkey tail (Anthurium cordatum), Begonia retusa en het mountaingrass (Scleria lithosperma) de bodem praktisch helemaal. De hellingen nabij de top van The Mountain zijn te steil voor deze vegetatie, die daar dan ook vervangen wordt door 'palm brake' waarin mountain cabbage (Euterpe globosa) sterk opvalt. 'Palm brake' moet beschouwd worden als een subclimax in het gebied van de montane formaties op plaatsen waar bodemverschuivingen veelvuldig voorkomen.

Het 'elfin woodland' wordt gekenmerkt door een lage boomlaag die bijna samenvalt met de heesterlaag; de takken zijn zeer grillig gevormd en begroeid met een dikke moslaag. Dit bostype wordt in het gehele Caraïbische gebied op de hoge toppen en kammen gevonden. Een soortenarm 'elfin woodland', gevormd door wild balsemtree (Clusia alba), wordt gevonden op de kraterrand van The Quill, terwijl een veel soorten-rijker 'elfin woodland', een Freziera-Rapanea gezelschap, met veel epiphytische varens en veel Anthurium en Philodendron, op de top van The Mountain aanwezig is.

Seizoen formaties. - De met het regenbos nauw verwante 'evergreen' en 'semi-evergreen seasonal forests' worden op St. Eustatius in de krater van The Quill, respectievelijk op de buitenhelling gevonden. Nauw hiermee verwant is ook de vegetatie nabij de top van Sentry Hill op St. Maarten.

Deze bossen vertonen veel overeenstemming met door STEHLÉ (1938) voor Martinique en door GoodiNg (1944) voor Barbados beschreven bossen. Loofverliezend seizoenbos komt nog voor op de helling van The Quill en op de hellingen rond Cul de Sac, St. Maarten. Voor zover er geen sprake is van cultuurland, is het merendeel van het laagland van St. Eustatius en St. Maarten begroeid met een doornig kreupelhout, dat duidelijk secundair is. Acacia, Malpighia, Pithecellobium en Capparis zijn belangrijke soorten. Sterk gedegradeerde bodems hebben een lage heester- 
vegetatie, waarin wild marrow (Croton astroites), yellow balsem (Croton flavens), sage (Lantana camara en L.involucrata), naast popeheads (Melocactus) en Opuntia een belangrijke rol spelen: de Croton-vegetatie. Deze vegetatie wordt ook op St. Eustatius - vooral in het heuvelgebied in het noord-westelijk deel van het eiland - en op Saba gevonden, maar is daar waarschijnlijk afgeleid van droge altijd-groene vegetatie typen. Cactus-struwelen en woestijn komen op de Bovenwindse Eilanden niet voor. Plaatselijk kunnen echter wel bijna ondoordringbare Opuntiastruwelen gevonden worden, die dan duidelijk een indicatie zijn voor verlaten cultuurgronden.

Droge altijd-groene formaties. - Van de 'dry evergreen formations' is het 'dry evergreen forest', het 'evergreen bushland' en de 'vegetation of the rock pavement' vertegenwoordigd. Het eerstgenoemde bos is nog het best ontwikkeld op de rand van de krater van The Quill, maar ook hier vinden we duidelijke aanwijzingen voor anthropogene invloeden. De bridgo tree (Linociera caribaea), sweet wood (Nectandra coriacea), black sweetwood (Nectandra krugii), white cedar (Tabebuia pallida), red wood (Inga laurina), maho (Daphnopsis caribaea), iron berry (Krugiodendron ferreum) en crack open (Casearia decandra) zijn o.a. veel voorkomende soorten in de twee boomlagen. Het bos is opvallend open; op de bodem veel grote stenen, die bedekt zijn door mossen. Een groot deel van de eilanden, vooral de steilere hellingen, is begroeid met vegetatie waarin bomen en hoge heesters voorkomen zonder dat van een bepaalde structuur sprake is. Aan de hand van de kenmerken die deze soorten vertonen moet men besluiten dat deze begroeiïng door menselijke invloed uit het 'dry evergreen forest' is ontstaan. De heuvels in het N.W.deel van St. Eustatius, Parish Hill en Great Hill op Saba en het gebied tussen Experiment en Guana Bay op St. Maarten geven hiervan mooie voorbeelden.

Het 'evergreen bushland' komt in de Low Lands van St. Maarten voor. Zeer opvallend zijn o.a. white frangepan (Plumiera alba), pepper cinnamon (Canella alba), Jacquinia berteri, Phyllanthus epiphyllanthus en Coccoloba krugii. Een doornig kreupelhout komt in dit gebied voor onder invloed van de mens; crabwood (Pithecellobium) en casha (Acacia farnesiana) zijn dan de meest op de voorgrond tredende soorten. Tot dit 'evergreen bushland' wordt ook gerekend de vegetatie op White Wall Bovendien moet het kustbos dat langs verschillende stranden op St. Maarten en bij Venus Bay en Concordia Bay, St. Eustatius, voorkomt tot 'evergreen bushland' gerekend worden. Dit kustbos bestaat voornamelijk uit sea grape (Coccoloba uvifera). Het is een eindstadium in de successie die begint met een open begroeiïng van sea vine (Ipomoea pescaprae) en sea peas (Canavalia maritima) en via een strand heestervegetatie met vooral sea purslane (Tournefortia gnaphalodes) en Suriana maritima in kustbos overgaat. Deze successie is alleen op zandstranden duidelijk te volgen.

Tenslotte vindt men uit deze formatie reeks nog de 'vegetation of the rock pavement' met enkele verspreide struikjes Strumpfia maritima, bitter pod (Urechites lutea) en picrous bark (Jacquinia barbasco), op de helling van Sugar Loaf en iets rijker gevormd op kalksteen bij Oysterpond, St. Maarten. 
Moeras formaties. - Hiertoe kunnen de mangrove bossen gerekend worden. Door de invloed van de mens zijn de Rhizophora- en Avicennia-gordels niet goed meer te onderscheiden. Meerdere halophyten kunnen langs de landzijde gevonden worden.

\section{Benedenwindse Eilanden.}

Op deze eilanden vinden we vegetaties uit de seizoen formaties, de droge, altijd-groene formaties en de moerasformaties.

Seizoen formaties. - Deze groep wordt, met als beste representant, vertegenwoordigd door het loofverliezende seizoenbos, dat op de helling van de Seroe Christoffel zeer mooi aanwezig is. Opvallend zijn hier de velden tecu (Bromelia lasiantha) die de ondergroei vormen en het groot aantal soorten dat elders op Curaçao niet aangetroffen wordt. Het diabaas-gebied is verder begroeid met tot seizoenformaties behorende vegetaties. Doornig kreupelhout met divi divi (Caesalpinia coriaria), wabi (Acacia tortuosa), uña di gatu (Pithecellobium unguis-cati), indju (Prosopis juliflora), en brazia (Haematoxylon brasiletto) zijn de meest voorkomende soorten. Afgeleid hiervan door sterke degradatie is de Croton-vegetatie: een lage heesterlaag met vooral welisali (Croton flavens) een flor di sanger (Lantana) waarboven hoge heesters en bomen uitsteken. Frequent treden cactus-struwelen op met cadushi di pushi (Cephalocereus lanuginosus), cadushi (Cereus repandus), datu (Lemaireocereus griseus) en Opuntia. Aan de loefzijde van de eilanden kunnen zelfs woestijnachtige landschappen ontstaan waar op grote, kale vlakten sporadisch een cactus of een kleine heester gevonden wordt, maar na regenbuien open grasvegetaties kunnen voorkomen.

Droge altijd-groene formaties. - Op de kalkplateau's vinden we vegetaties die tot deze reeks behoren.

In de best ontwikkelde en minst aangetaste voorbeelden is dit een 'dry evergreen woodland' dat overeenkomt met 'scrub woodland derived from dry evergreen forest' (BEARD, 1949). Het 'dry evergreen bushland' wordt gevormd door een heesterlaag, waarboven verspreide bomen uitsteken. Beshi di kalakuna (Coccoloba swartzii), manzanilla bobo (Metopium brownei), cuchara (Antirrhoea acutata), basora pretu (Cordia cylindrostachya) en placa chiquitu (Rhacoma crossopetalum) zijn opvallende soorten. Ook het kustbos, dat hier op de eilanden slechts spaarzaam aanwezig is, moet hiertoe gerekend worden. Het normale type, gevormd door zeedreifi (Coccoloba uvifera), komt voor, maar daarnaast ook een vorm waarin placa chiquitu (Rhacoma crossopetalum) domineert. Dit laatste type kustbos op een zandbodem wordt ook vermeld door RAUNKIAER (1934) voor St. Croix en door Asprey \& RobBins (1953) voor Jamaica. De Ipomoea pes-caprae - Canavalia maritima vegetatie is slechts spaarzaam ontwikkeld evenals de Tournefortia - Suriana vegetatie.

Doornig kreupelhout komt op de kalkplateau's ook voor, maar dan als secundaire vegetatie. Een duidelijk verschil met het doornig kreupelhout uit de seizoenformaties is het steeds voorkomen van cuchara ( $A n$ - 
tirrhoea acutata), lumbra blancu (Erithalis fruticosa), en veel meer basora pretu (Cordia cylindrostachya) in de heesterlaag indien deze aanwezig is. Ook in de Croton-vegetatie op de kalkplateau's zijn deze soorten wel steeds vertegenwoordigd. 'Vegetation of the rock pavement' wordt op de drie eilanden vooral langs de noordkust gevonden.

Moeras formaties. - Evenals op de Bovenwindse Eilanden zijn deze formaties slechts vertegenwoordigd door mangrove. Speciaal op Bonaire bij Lac is een zonering in Rhizophora-, Avicennia- en Laguncularia-zône zeer duidelijk. Aan de landzijde van de mangroves worden dan nog halophyten gevonden o.a. banana di rif (Batis maritima) en Salicornia ambigua, die ook vaak langs de salinjas gevonden worden.

Beschrijvingen van deze vegetaties worden gegeven door STOFFERS (1956, 1957, 1958, 1960).

\section{OECOLOGISCH ONDERZOEK}

De derde fase in botanisch onderzoek heeft nog slechts op zeer beperkte schaal plaats gehad op de Benedenwindse Eilanden, terwijl op de Bovenwindse Eilanden in dit opzicht nog in het geheel niets ondernomen is.

Er mag aangenomen worden dat het macro-klimaat op CuRAÇAO, misschien met uitzondering van de Seroe Christoffel en omgeving, vrij eenvormig is. Verschillen in micro-klimaat van kalk- en diabaasgebieden zijn echter zeer groot (STOFFERS, I966). Juist boven het bodemoppervlak werden in het diabaasgebied maximum-temperaturen gemeten om I2.00 uur, maxima die op tegen wind beschermde plaatsen waarden van meer dan $70^{\circ} \mathrm{C}$ bereikten. Op $5 \mathrm{~cm}$ diepte wordt een temperatuur-verloop gevonden parallel hiermee, maar met een verschuiving van ca I uur. In tegenstelling hiermee wordt op overeenkomstige plaatsen in het kalkgebied een maximum-temperatuur gevonden van ca $40^{\circ} \mathrm{C}$, die echter vóór I2 uur reeds bereikt wordt en tot 15.00 uur aanhoudt. Op $5 \mathrm{~cm}$ diepte wordt het maximum eerst om I5.00-I6.00 uur bereikt, na een langzame, zeer geleidelijke stijging, en gevolgd door een langzame, lang aanhoudende daling. Nabij het bodemoppervlak treden in het kalkgebied dus minder extreme waarden op, hetgeen voor de ontwikkeling van kruiden en kiemplanten van grote betekenis is. Temperatuurverschillen in de lucht boven diabaas- en kalkbodems zijn echter op 70 en $200 \mathrm{~cm}$ hoogte zeer gering.

Op de verschillen tussen de vegetatie van het kalk- en het diabaas-gebied werd reeds gewezen. De vraag komt echter naar voren of dit het gevolg is van kalkminnende en kalkmijdende soorten. De verspreiding van deze 'kalkminnende' soorten over 
de eilanden, ook op andere eilanden van de Antillen, maakt dit echter zeer onwaarschijnlijk (STOFFERS, I963b). Uit onderzoek met betrekking tot transpiratie, water verzadigingsdeficiet en zuigspanning van de bladeren wordt geconcludeerd, dat de verschillen veroorzaakt worden door de hydratuur van de bodem (Stoffers, I966; Stoffers \& Mansour Elassaiss, i967). Een diabaas-bodem wordt in de regentijd snel met water verzadigd. De plant kan hieruit gemakkelijk water opnemen. Spoedig na het begin van de droge tijd zal het water uit een dergelijke bodem geheel verdwenen zijn en de planten werpen het loof af. In het kalkgebied wordt door de in spleten en scheuren aanwezige bodem - met een goed ontwikkeld klei-complex en dus een grote watercapaciteit - een grote hoeveelheid water vastgehouden. Planten die in staat zijn een hoge zuigspanning te ontwikkelen, kunnen hieruit het gehele jaar water onttrekken, temeer daar deze planten in de loop van de dag reeds snel een vermindering van transpiratie vertonen. Hierdoor kunnen de altijd-groene soorten zich wel in de kalkgebieden, maar niet in de diabaasgebieden handhaven.

Samenvattend kunnen wij dus zeggen, dat de botanische kennis van de Nederlandse Antillen in de laatste 20 jaren sterk is toegenomen. Een toename die voor een zeer groot deel te danken is aan activiteiten van de 'Studiekring' en betrekking heeft op:

I. de flora, waarbij de Benedenwindse Eilanden een gunstiger beeld vertonen dan de Bovenwindse Eilanden, dank zij groter locale activiteit;

2. de vegetatie, waarvan een algemeen beeld, ingepast in het Caraïbische gebied, gegeven werd, maar detail-onderzoek zeer gewenst is;

3. de oecologie, waarmee weliswaar pas een eerste begin is gemaakt, maar die reeds resultaten opleverde welke een verder onderzoek rechtvaardigen. 


\section{LITERATUUR}

Amshoff, G. J. H., 1942. The Grasses of the Dutch West Indian Islands. Meded. Afd. Handelsmuseum Koloniaal Instituut 59, Amsterdam.

Amshoff, G. J. H., 1950. Notes on Guiana Myrtaceae III. Recueil Trav. bot. néerl. 42, p. I-27.

Arnoldo, Frater M. (A. N. Broeders). 1954. Gekweekte en nuttige planten van de Nederlandse Antillen. Uitgaven Natuurwet. Werkgroep Ned. Ant. 3. Martinus Nijhoff, 's-Gravenhage. I49 pp., 63 pl.

ARnoldo, Frater M., 1954. Zakflora. Wat in het wild groeit en bloeit op Curaçao, Aruba en Bonaire. Uitgaven Natuurwet. Werkgroep Ned. Ant. 4, I7I pp., 68 pl. - Ed. 2. Uitg. I6, I964, 232 pp., 68 pl. - Nijhoff, 's-Gravenhage.

Arnoldo, Frater M. \& Wagenaar Hummelinck, P., 1936. Over Hylocereus undatus. Succulenta I8, p. II4-II8.

Asprey, G. F. \& Robbins, R. G., 1953. The Vegetation of Jamaica. Ecol. Monogr. 23, p. 359-4I I.

Beard, J. S., 1944. Climax Vegetation in Tropical America. Ecology 25, p. $127^{-1} 5^{8}$.

BeARD, J. S., 1949. The Natural Vegetation of the Windward and Leeward Islands. Oxford For. Mem. $2 I$.

Beard, J. S., 1955. The Classification of Tropical American Vegetationtypes. Ecology 36, p. 89-100.

Boldingh, I., 1909. The Flora of the Dutch West Indian Islands. Vol. I. The Flora of St. Eustatius, Saba and St. Martin. Leiden; Acad. Thesis Utrecht.

BoldingH, I., I9I3. Flora voor de Nederlandsch West-Indische Eilanden. Amsterdam.

Boldingh, I., I9I4. The Flora of the Dutch West Indian Islands. Vol. II. The Flora of Curaçao, Aruba and Bonaire. Leiden.

Charter, C. F., I94I. A reconnaissance Survey of the Soils in British Honduras. Trinidad.

Chase, A., 1943. New grasses from South America. Journ. Wash. Acad. Sci. 33, p. 316-317.

Díaz-Piferrer, M., I964. Adiciones a la flora marina de las Antillas Holandesas Curazao y Bonaire. Caribb. J. Sci. 4, p. 513-543.

Frémy, P., I94I. Cyanophycées des îles Bonaire, Curaçao et Aruba ... Revue Algol. I2, p. IoI-152. (Zie ook W.I. Gids 27, 1944, p. 62-64).

Florschürz, P. A., 1967. Mosses from the Netherlands Antilles. Acta Bot. Neerl. 15, p. 524-529.

Gooding, E. G. B., 1944. Turner's Hall Wood, Barbados. Car. For. 5, p. $153-170$.

Hardy, F., I946. The Evaluation of Soil Moisture. Trop. Agr. 23, p. 66-75. 
Henrard, J. Th. A., 1926. A critical revision of the genus Aristida. Meded. Rijksherb. Leiden 54, 220 pp.

Henrard, J. Th. A., I943. On a new species of Paspalum from the island of Bonaire. Blumea 5, p. 324-327.

Hовк, C. v. D., 1959. Caribbean fresh and brackish water Chlorophyta. Blumea 9, p. 590-625.

JAcQuin, 1763. Selectarum Stirpium Americanarum historia.

Koster, J. TH., 1960. Caribbean brackish and freshwater Cyanophyceae. Blumea ro, p. 323-366.

Linnaeus, C., 1753. Species Plantarum.

Lanjouw, J. \& Wessels Boer, J. G., 1962. In Burger, Lanjouw \& Wessels Boer, The genus Sorocea St. Hil. (Morac.) Acta Bot. Neerl. $I I$, p. $428-477$.

Monachino, J. S., 1947. A new Species of Xylosma from Curaçao. Car. For. 8, p. 237-239.

Mонг, E. C. J., 1944. The Soils of Equatorial Regions. Michigan.

Moldenke, H. N., I940. Some new species and varieties of Verbenaceae. Car. For. 2, p. 13-17.

Moldenke, H. N., I940. Novelties among the American Verbenaceae. Phytologia I, p. 453-48o.

Plukenet, L., I696. Opera omnia botanica phytographia IV.

RAUnkiAer, C., I934. The life-forms of plants and statistical plant geography. Oxford.

Realino, Frater M., 1935. Plantkunde van Curaçao voor M.U.L.O. Curaçao [III. '36], I33 pp. - 2e druk, I947 [I. '48], I88 pp.

Sluiter, C. P., 1908. List of algae collected by the Fishery Inspection at Curaçao. Recueil Trav. bot. néerl. 4, p. 23I-24I.

Stehlê, H., I938. Esquisse des associations végetales de la Martinique. Bull. Agr. Martinique 6, p. 194-264.

Stoffers, A. L., 1956. The vegetation of the Netherlands Antilles. Uitgaven Natuurwet. Studiekring Sur. N.A. I5, 142 pp., 28 pl., 4 gekl. krtn. (Thesis Utrecht).

Stoffers, A. L., 1957. De vegetatie van Aruba, Bonaire en Curaçao. Oost en West 5o, p. 6-8. - 1958. De Bovenwindse Eilanden der Nederlandse Antillen. O.W. 5I, p. 27-28.

Stoffers, A. L., I960. Het plantenkleed. De Nederlandse Antillen. Schakels NA 33, p. I-32.

Stoffers, A. L. (ed.), 1962. Flora of the Netherlands Antilles $I$ (I), p. I-84; 1963, $I(2)$, p. $85-203$; 1966, $I I(I)$, p. I-96; $\rightarrow$. Uitg. Natuurwet. Stud. Sur. N.A. $25,36,42$.

Stoffers, A. L., 1963a. A new species of Alternanthera from Curaçao. Neth. Ant. Acta Bot. Neerl. 12, p. 73-75. 
Stoffers, A. L., I963b. Enige opmerkingen over de vegetatie van Bonaire. Versl. Meded. Kon. Ned. Bot. Ver. I962, p. 44.

Stoffers, A. L., 1966. Plant sociological and ecological research in Aruba, Curaçao and Bonaire. Report 1964 and 1965 , WOTRO, p. 4 I-43.

Stoffers, A. L. \& Mansour Elassaiss, C. J. M., I967. On the water relation in limestone and diabase vegetation in the Leeward Islands of the Netherlands Antilles. Acta Bot. Neerl. 15, p. 539-556.

Suringar, W. F. R., I886. Melocacti novi ex insulis archipelagi Indicioccidentalis Neerlandicis Curaçao, Aruba et Bonaire. Versl. Meded. Ak. Wet. Amsterdam, Natuurk. (3) 2, p. 183-195.

Suringar, W. F. R., I889. Nieuwe bijdragen tot de kennis der melocacti van West-Indië. Versl. Meded. Ak. Wet. (3) 6, p. 408-437.

Suringar, W. F. R., r889. Melocacti novi ex insula Aruba ... Versl. Meded. Ak. Wet. (3), 6, p. 438-46r.

Suringar, W. F. R., I892. Derde bijdrage ... Versl. Meded. Ak. Wet. (3) 9, p. 406-412.

Suringar, W. F. R., I 896 . Vierde bijdrage ... Versl. Meded. Ak. Wet. (2) $5,3,46$ pp.

Suringar, W. F. R., I897. Vijfde bijdrage ... Versl. Vergad. Ak. Wet. 6, p. $178-192$.

Suringar, W. F. R., I897. Illustrations du genre Melocactus. I. Musée Botanique de Leide. Tab. I-8.

Suringar, J. Valckenier, I9oi. Contributions à l'étude des espèces du genre Melocactus des Indes Néerlandaises occidentales. Verh. Ak. Wet. (2) 8, I, 40 pp.

Suringar, J. Valckenier, I903. Het Melocactus onderzoek. Nederl. Kruidk. Archief (3) 2, p. 1047-1058.

Suringar, J. VAlckenier, 1903. Illustrations du genre Melocactus. 2. Tab. 9-16. - 3, 1905, Tab. 17-23.

Suringar, J. Valckenier, I9io. Nouvelles contributions ... Verh. Ak. Wet. (2) $16,3,4^{\circ} \mathrm{pp}$.

TAYLOR, W. R., 1942. Caribbean marine algae of the Allan Hancock Expedition, 1939. Allan Hancock Atlantic Exp. Report 2, I93 pp.

VRoman, M., I959. Onderzoek naar het voorkomen en de oecologie van de mariene wieren der Nederlandse Antillen. Jaarbericht 1958 WOSUNA, p. $3^{8-39 .}$

[WagenaAR] Hummelinck, P., I93I. Over het gebruik van cactussen op Bonaire. Succulenta I3, p. 4I-5I. - I933. Cactusfasciaties van Aruba, Curaçao en Bonaire. Succ. I5, p. 183-190.

WagenaAR Hummelinck, P., r934. Over de cactussen van Curaçao, Aruba en Bonaire. Succulenta 16, p. 145-153, I6I-168.

WagenaAr Hummelinck, P., I935. Over het voorkomen van Acanthocereus pentagonus op Curaçao. Succulenta I7, p. 65-72. - Over Opuntia curassavica. Succ. 17, p. $81-83$. 
Wagenaar Hummelinck, P., 1936. Notes on Agave in Aruba, Curaçao, Bonaire and some parts of the South American continent. Recueil Trav. bot. néerl. 33, p. 223-249. - 1938. Notes on Agave in the Netherlands West Indies and North Venezuela. Rec. 35, p. 14-28.

WagenaAr Hummelinck. P., 1938. Notes on the Cactaceae of Curaçao, Aruba, Bonaire and North Venezuela. Recueil Trav. bot. néerl. 35, p. 29-55.

Wagenaar Hummelinck, P., I938. Over Cereus repandus, Cephalocereus lanuginosus, Lemaireocereus griseus en Acanthocereus tetragonus. Succulenta 20, p. I33-140, I49-156, I65-171. - r940. Over Opuntia curassavica, O. wentiana, O. elatior en Mammillaria simplex. Succ. 22, p. I 2I-I 29, I37-I43. - I94I. Lijst voor het vinden van de soortsnamen van de op de Benedenwindsche Eilanden voorkomende cactussen. Succ. 23., p. I $2 \mathrm{I}-\mathrm{I} 28$.

WagenaAr Hummelinck, P., 1942. Het Melocactus-onderzoek. Gedenkboek J. Valckenier Suringar, Nederl. Dendrol. Vereniging, p. 88-95. 